\title{
Effect of Sulodexide on Vascular Responses and Liver Mitochondrial Function in Diabetic Rats
}

\author{
L. DOBIA ̌́ ${ }^{1}$, M. PETROVÁ ${ }^{1}$, R. VOJTKO ${ }^{1}$, O. ULIČNÁ ${ }^{2}$, O. VANČOVÁ ${ }^{2}$, V. KRISTOVÁ ${ }^{1}$ \\ ${ }^{1}$ Department of Pharmacology and Clinical Pharmacology, Comenius University, Bratislava, \\ Slovak Republic, ${ }^{2}$ Pharmacobiochemical Laboratory of Third Department of Internal Medicine, \\ Comenius University, Bratislava, Slovak Republic
}

Received September 13, 2015

Accepted October 12, 2015

\section{Summary}

This study investigates the effects of long-term treatment with sulodexide (SLX) on norepinephrine (NE)-induced contractions, acetylcholine(Ach)-induced relaxations, acute cyclooxygenase blockade by diclofenac (DIC) in isolated femoral arteries (FA) and the parameters of oxidative phosporylation in liver mitochondria. 15-weeks old Wistar rats were divided into four groups: control ( $C$; injected with saline solution), treated control $(C+S L X)$, diabetic (DM) and treated diabetic (DM+SLX). Diabetes was induced with a single i.v. dose of streptozotocin (STZ) $45 \mathrm{mg} \cdot \mathrm{kg}^{-1}$. SLX was administered i.p., at dose $100 \mathrm{IU} \cdot \mathrm{kg}^{-1}$ daily for 5 weeks. Vascular responses of isolated femoral arteries were measured using Mulvany-Halpern myograph. Respiratory function of the mitochondria was determined using voltamperometric method on oxygraph Gilson. In diabetic rats the amplitude of maximal response to NE was elevated. DIC pretreatment decreased the amplitudes of $\mathrm{NE}$-induced contractions in all groups of rats. SLX treatment decreased sensitivity of FA to NE and caused higher relaxatory responses to Ach in $C$ and DM. Oxygen consumption and phosphorylation rates $\left(\left[\mathrm{QO}_{2}\left(\mathrm{~S}_{3}\right)\right]\right.$, $\left[\mathrm{QO}_{2}\left(\mathrm{~S}_{4}\right)\right]$ and (OPR)) and respiratory control ratio (RCR) were decreased in the mitochondria of DM rats. Mitochondria of $C$ rats were not affected with SLX treatment. Administration of SLX in DM rats was associated with increase of RCR, other parameters were not affected. Our findings suggest that SLX treatment might be associated with vasculoprotective effects during diabetes and improvement of mitochondrial function.

\section{Key words}

Vascular response • Diabetes mellitus • Sulodexide • Endothelium - Oxidative phosphorylation

\section{Corresponding author}

L. Dobiaš, Department of Pharmacology and Clinical Pharmacology, Faculty of Medicine, Comenius University, Sasinkova 4, 81372 Bratislava, Slovak Republic. E-mail: lukas.dobias@fmed.uniba.sk

\section{Introduction}

Micro- and macrovascular diseases are currently the major causes of morbidity and mortality in patients with type 1 and type 2 diabetes mellitus (DM) (De Vriese et al. 2000). The vascular endothelium is a multifunctional organ and is critically involved in modulating vascular tone, cellular adhesion, thrombogenesis, smooth muscle cell proliferation and vessel wall inflammation. Thus, endothelial function is important for the homeostasis of the body and its dysfunction is associated with several pathophysiological conditions including DM (Sena 2013). On this basis, the vascular endothelium has emerged as a therapeutic target, where the intent is to improve systemic metabolic state by improving vascular function. Therapy that improves endothelial function has the potential to simultaneously benefit both vascular and metabolic disease (Mather 2013). The therapeutic approach to DM should also be focused on the reduction of the risk factors for cardiovascular diseases as hypertension and dyslipidemia using antihypertensives, hemorrheologics and hypolipidemics. Another therapeutic approach consists in targeting metabolic improvements by augmenting insulin vascular function. Several nonpharmacological and pharmacological 
approaches have been demonstrated to improve or reverse endothelial dysfunction, although their effect is never selective and usually also targets one or more traditional cardiovascular risk factors (Versari et al. 2009). The endothelial glycocalyx, layer composed by proteoglycans covering luminal surface of vascular endothelium forms a barrier against atherosclerotic stimuli (Broekhuizen et al. 2010). Shredding of glycocalyx is an essential initial step in the pathophysiology of microvascular complications especially in conditions as diabetes mellitus. Treatment with glycosaminoglycans has been shown to prevent or recover the damaged glycocalyx and several of its consequences (Frati Munari et al. 2014). The favourable effects of sulodexide (SLX), a mixture of heparin-like and dermatan fractions, has been evaluated on certain types of vasculature in various experimental models of endothelial damage. Sulodexide has been shown to significantly decrease the number of desquamated endothelial cells in vitro (Kristová et al. 2000) and to improve endothelium-dependent relaxation of mesenteric arteries (Kristová et al. 2008) and reverse morphological alterations in intima and adventitia of aortic artery (Vásquez et al. 2010) in streptozotocininduced diabetes. We therefore aimed to examine the effects of SLX on endothelial function of femoral arteries in the model of experimental streptozotocininduced diabetes in rats. It is well known that DM represents a metabolic burden for the liver. Chronic hyperglycemia causes an overproduction of free radicals via auto-oxidation of glucose, non-enzymatic protein glycation and enhanced flux of glucose through the polyol pathway. In DM liver mitochondria exhibit morphological and functional abnormalities (Huang et al. 2001). Since SLX is being metabolized in the liver (Marchi et al. 1994) and there are no research data dealing with in vivo effects of SLX on mitochondrial function in liver, we decided to study whether long-term administration of SLX affects respiratory function and energy production in the liver mitochondria in the healthy and diabetic rats.

\section{Materials and Methods}

\section{Chemicals}

Potassium chloride, potassium dihydrogen phosphate, 2-[4-(2-hydroxyethyl)-1-piperazinyl]-ethansulfonate acid (HEPES) and ethylenedinitrilotetraacetic acid disodium salt (Titriplex III), were obtained from
Merck, adenosine-5-diphosphate sodium salt (ADP), streptozotocin, sodium chloride, magnesium sulphate, sodium hydrogencarbonate, ethylenediaminetetraacetic acid, calcium chloride, ascorbic acid and glucose were obtained from Sigma, sulodexide (Vessel Due F, inj 600 LSU amp.) was obtained from Alfa Wasserman.

\section{Animals}

15 weeks old Wistar male rats (300-370 g) were obtained from facility Dobrá voda, SAV. They were housed under standard laboratory conditions (temperature $23 \pm 1{ }^{\circ} \mathrm{C}, 12$-h light-dark cycle, controlled air humidity, standard pelleted diet and tap water ad libitum). The experiment was performed according to Guide for the Care and Use of Laboratory Animals (1985), European Guidelines on Laboratory Animal Care and was approved by the Local Ethics Committee on Animal Experiments and State veterinary institute.

\section{Experimental procedure}

Blood glucose and body weight were measured at the beginning of the experiment. Animals were randomly divided into four groups. The first group was an untreated control (C), the second group was treated with sulodexide (C+SLX, $100 \mathrm{UI} / \mathrm{kg} /$ day). Diabetes was induced with single dose of streptozotocin $\left(45 \mathrm{mg} \cdot \mathrm{kg}^{-1}\right.$ of body weight dissolved in $0.1 \mathrm{~mol}^{-1}$ citrate buffer, $\mathrm{pH}$ 4.5) administered intravenously via the tail vein. Rats with ad libitum access to food were after $48 \mathrm{~h}$ characterized by the levels of blood glucose measured by Bayer Contour TS meter. Animals with blood glucose concentration $>16 \mathrm{mmol}^{-1}$ were considered diabetic, and were included in the study. Third group was injected with physiological solution (DM) and the fourth group was treated with sulodexide (DM+SLX, $100 \mathrm{UI} / \mathrm{kg} /$ day). Treatment with sulodexide started on the seventh day after induction of diabetes and lasted for 5 weeks. Thereafter, blood glucose levels were determined in same conditions as at the beginning of the experiment. The animals were sacrificed by intraperitoneal application of thiopental $\left(50 \mathrm{mg} \cdot \mathrm{kg}^{-1}\right)$.

\section{Measurement of vascular responses of femoral arteries}

Isolated femoral arteries with intact endothelium were cut into $2 \mathrm{~mm}$ long segments and mounted in the chamber of Mulvany Halpern isometric myograph. The myograph chamber was filled with modified Krebs-Ringer solution (in mmol. ${ }^{-1}$ : $\mathrm{NaCl} 119$, $\mathrm{KCl} 4.7, \quad \mathrm{MgSO}_{4} 25, \quad \mathrm{KH}_{2} \mathrm{PO}_{4} 1.2, \quad$ glucose 11.1, 
$\mathrm{CaCl}_{2} 2.5$, EDTA 0.03 at $37{ }^{\circ} \mathrm{C}$, gased with $95 \% \mathrm{O}_{2}$ and

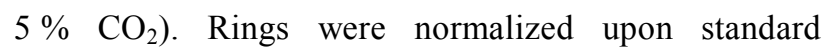
procedures (Angus and Wright 2000) to achieve their basal tone and after 30 min incubated with depolarising solution (in mmol.1 ${ }^{-1}: \mathrm{K}^{+} 124$ and $\mathrm{Na}^{+} 2.5$ ) to provide maximal depolarisation-induced contraction followed by washout period to achieve constant basal tone. Further contractions were provided with cumulative applied doses of norepinephrine (NE; in mol.1 ${ }^{-1}: 3.10^{-7}$, $10^{-7}, 3.10^{-6}, 10^{-6}, 3.10^{-5}, 10^{-5}, 3.10^{-4}$ and $10^{-4}$ ). Relaxations were induced with single dose of acetylcholine (ACH; 3.10 $0^{-6} \mathrm{~mol}^{-1}$ ). The same protocol was used in the presence of diclofenac (DIC; $0.01 \mathrm{mol.} \mathrm{1}^{-1}$, incubation time $15 \mathrm{~min}$ ).

\section{Isolation and measurement of mitochondrial function}

Mitochondria were isolated from freshly excised livers by differential centrifugation as described by Hogeboom (1955), with some modification. The isolation medium was prepared according to Sammut et al. (1998), with the following modification (in mmol. $1^{-1}$ ): mannitol 225, sucrose 75 and Titriplex III 0.2 . Liver was minced in the isolation medium $(\mathrm{pH} 7.4$ at $4{ }^{\circ} \mathrm{C}$ ) and homogenized using a teflon-to-glass homogenizer. The homogenate was centrifuged at $700 \mathrm{~g}$ for $10 \mathrm{~min}$, the supernatant was decanted and centrifuged at $5600 \mathrm{~g}$ for $10 \mathrm{~min}$. The mitochondrial pellet was washed twice with isolation medium. The resulting pellet was resuspended in the same medium to a final protein concentration of $20-40 \mathrm{mg} \cdot \mathrm{ml}^{-1}$. All procedures were performed at $4{ }^{\circ} \mathrm{C}$. Proteins were determined according to Lowry et al. (1951).

Respiratory function of the mitochondria was determined using the voltamperometric method on oxygraph Gilson 5/6 H (USA) using Clark oxygen electrode at $30^{\circ} \mathrm{C}$. The incubation medium was prepared as described by Rouslin and Millard (1980) with a modification: in mmol. $1^{-1}$ : HEPES $12.5, \mathrm{KCl} 122$, $\mathrm{KH}_{2} \mathrm{PO}_{4} 3$, Titriplex III 0.5 and $2 \%$ dextran. Glutamate/ malate at $2.5 \mathrm{mmol}^{-1}$ was used as a NAD substrate. For assessing stimulated oxygen consumption, $500 \mathrm{nmol}$ of ADP was added. The following parameters of oxidative phosphorylation were determined in the liver mitochondria: respiratory control ratio (RCR), coefficient of oxidative phosphorylation (ADP:O), the rate of oxygen uptake by the mitochondria stimulated with ADP - state $3\left[\mathrm{QO}_{2}\left(\mathrm{~S}_{3}\right)\right]$, the rate of basal oxygen uptake by mitochondria without ADP - state 4
$\left[\mathrm{QO}_{2}\left(\mathrm{~S}_{4}\right)\right]$ and the oxidative phosphorylation rate (OPR) (Estabrook 1967).

\section{Statistical analysis}

Data are expressed as arithmetical mean \pm SEM. Statistical analyses were performed with one- and two-way ANOVA tests, Student's t-test and post-hoc Bonferroni test. $\mathrm{P}<0.05$ was considered as a significant difference.

\section{Results}

The weight of the rats in all groups at the beginning of the experiment was not significantly different. At the end of the experiment, rats in the diabetic group had significantly lower body weight compared to the healthy groups $(\mathrm{P}<0.05)$. Concentration of glucose increased significantly in both diabetic groups. SLX treatment did not affect postprandial glycemia in diabetic rats. In control rats, SLX treatment resulted in significantly lower increase of glycemia compared to untreated controls (Table 1).

\section{Vascular responses of femoral arteries}

The administration of cumulative concentrations of norepinephrine to femoral arteries elicited concentration-response curves which were similar in vessels obtained from control rats, and control rats treated with sulodexide (Fig. 1A). In diabetic rats, the norepinephrine-induced dose-response curves were significantly shifted to the left $(\mathrm{P}<0.05)$, the amplitude of contraction elicited by the highest dose of $\mathrm{NE}\left(10^{-4} \mathrm{~mol}^{-1} \mathrm{l}^{-1}\right)$ and sensitivity to NE were significantly enhanced (both $\mathrm{P}<0.05$ ) compared to control rats (Fig. 1B). Diabetic rats were characterized by a steeper slope of dose-response curves, while treatment with SLX significantly reduced the slope of the curves $(\mathrm{P}<0.05)$. The norepinephrine-induced concentration-response curves were almost abolished in control groups $(\mathrm{P}<0.001)$ and significantly diminished in diabetic groups of rats $(\mathrm{P}<0.001)$ following pretreatment of vessels with diclophenac. The amplitude of contraction elicited by the highest dose of $\mathrm{NE}$ $\left(10^{-4}\right.$ mol. $\left.1^{-1}\right)$ was not affected by SLX treatment significantly $(\mathrm{P}>0.05)$, although sensitivity to norepinephrine $\left(\mathrm{pEC}_{50}\right)$ was significantly decreased compared to untreated diabetic rats (Fig. 1, Table 1). 
Table 1. The body weights, glucose concentrations and pharmacodynamic parameters of norepinephrine and acetylcholine concentration response curves determined in femoral arteries of control and diabetic rats.

\begin{tabular}{|c|c|c|c|c|}
\hline & $\begin{array}{c}\mathbf{C} \\
(\mathrm{n}=10)\end{array}$ & $\begin{array}{c}\text { C+SLX } \\
(\mathrm{n}=9)\end{array}$ & $\begin{array}{c}\text { DM } \\
(\mathrm{n}=13)\end{array}$ & $\begin{array}{c}\mathbf{D M}+\mathbf{S L X} \\
(\mathrm{n}=14)\end{array}$ \\
\hline Weight (1) (g) & $322.6 \pm 5.8$ & $330.7 \pm 6.3$ & $332.2 \pm 5.2$ & $322.8 \pm 4.1$ \\
\hline Weight (2) (g) & $370.4 \pm 7.5$ & $377 \pm 9.4$ & $255 \pm 9.2^{\mathrm{a}, \mathrm{b}}$ & $240.2 \pm 12.5^{\mathrm{a}, \mathrm{b}}$ \\
\hline Weight gain (\%) & $12.8 \pm 0.6$ & $12.1 \pm 0.4$ & $-31.9 \pm 2.2^{\mathrm{a}, \mathrm{b}}$ & $-37.9 \pm 3.3^{\mathrm{a}, \mathrm{b}}$ \\
\hline Glycemia (1) $\left(\right.$ mmol..$\left.^{-1}\right)$ & $4.9 \pm 0.1$ & $5.2 \pm 0.1$ & $21.9 \pm 1.6^{\mathrm{a}, \mathrm{b}}$ & $22.7 \pm 1.5^{\mathrm{a}, \mathrm{b}}$ \\
\hline Glycemia (2) (mmol. $\left.l^{-1}\right)$ & $5.3 \pm 0.2$ & $5.3 \pm 0.2$ & $32.2 \pm 0.9$ & $32.9 \pm 0.5$ \\
\hline $\begin{array}{l}\text { NE }\left(3.10^{-4} \text { mol. } \mathrm{l}^{-1}\right) \text { induced maximal } \\
\text { contraction }\left(\mathrm{mN} . \mathrm{mm}^{-1}\right)\end{array}$ & $2.03 \pm 0.21$ & $1.53 \pm 0.19^{\mathrm{a}}$ & $5.11 \pm 0.27^{\mathrm{a}, \mathrm{b}}$ & $5.37 \pm 0.25^{\mathrm{a}, \mathrm{b}}$ \\
\hline$p E C_{50}\left(\log\right.$ mol..$\left.^{-1}\right)$ & $4.23 \pm 0.12$ & $4.20 \pm 0.14$ & $5.08 \pm 0.05^{\mathrm{a}, \mathrm{b}}$ & $4.78 \pm 0.19^{\mathrm{a}, \mathrm{b}, \mathrm{c}}$ \\
\hline Slope & $1.03 \pm 0.28$ & $1.03 \pm 0.33$ & $1.57 \pm 0.04^{\mathrm{a}, \mathrm{b}}$ & $1.16 \pm 0.03^{\mathrm{a}, \mathrm{c}}$ \\
\hline $\begin{array}{l}A C H\left(3.10^{-5} \text { mol. } .^{-1}\right) \text { induced } \\
\text { relaxation of NE-precontracted } \\
\text { vessels }(\%)\end{array}$ & $80.06 \pm 4.39$ & $87.22 \pm 6.45$ & $63.24 \pm 6.10^{\mathrm{b}}$ & $64.27 \pm 2.55^{\mathrm{b}}$ \\
\hline $\begin{array}{l}\text { ACH }\left(3.10^{-5} \text { mol. } .^{-1}\right) \text { induced wall } \\
\text { tension decrease }\left(\mathrm{mN} \mathrm{mm}^{-1}\right)\end{array}$ & $1.63 \pm 0.17$ & $1.26 \pm 0.15$ & $3.10 \pm 0.17^{\mathrm{a}, \mathrm{b}}$ & $3.15 \pm 0.18^{\mathrm{a}, \mathrm{b}}$ \\
\hline$E_{\max }$ reduction elicited by DIC (\%) & $93.55 \pm 0.97$ & $88.63 \pm 3.06$ & $63.01 \pm 2.34^{\mathrm{a}, \mathrm{b}}$ & $80.20 \pm 1.51^{\mathrm{a}, \mathrm{c}}$ \\
\hline
\end{tabular}

Values presented as arithmetic mean $\pm \mathrm{SEM}, \mathrm{C}$ - control group, $\mathrm{C}+\mathrm{SLX}$ - control group treated with sulodexide, DM - diabetic group, $\mathrm{DM}+\mathrm{SLX}$ - diabetic group administered with sulodexide, $\mathrm{ACH}$ - acetylcholine, DIC - diclophenac, NE - norepinephrine, $\mathrm{pEC}_{50}-$ negative logarithm of EC50 (half maximal effective concentration). Glycemia and weight were measured $48 \mathrm{~h}$ after application of STZ (1) and before sacrifice (2). Statistical significance: ${ }^{a} \mathrm{P}<0.05$ vs. $C,{ }^{b} \mathrm{P}<0.05$ vs. $\mathrm{C}+\mathrm{SLX},{ }^{\mathrm{c}} \mathrm{P}<0.05$ vs. DM.
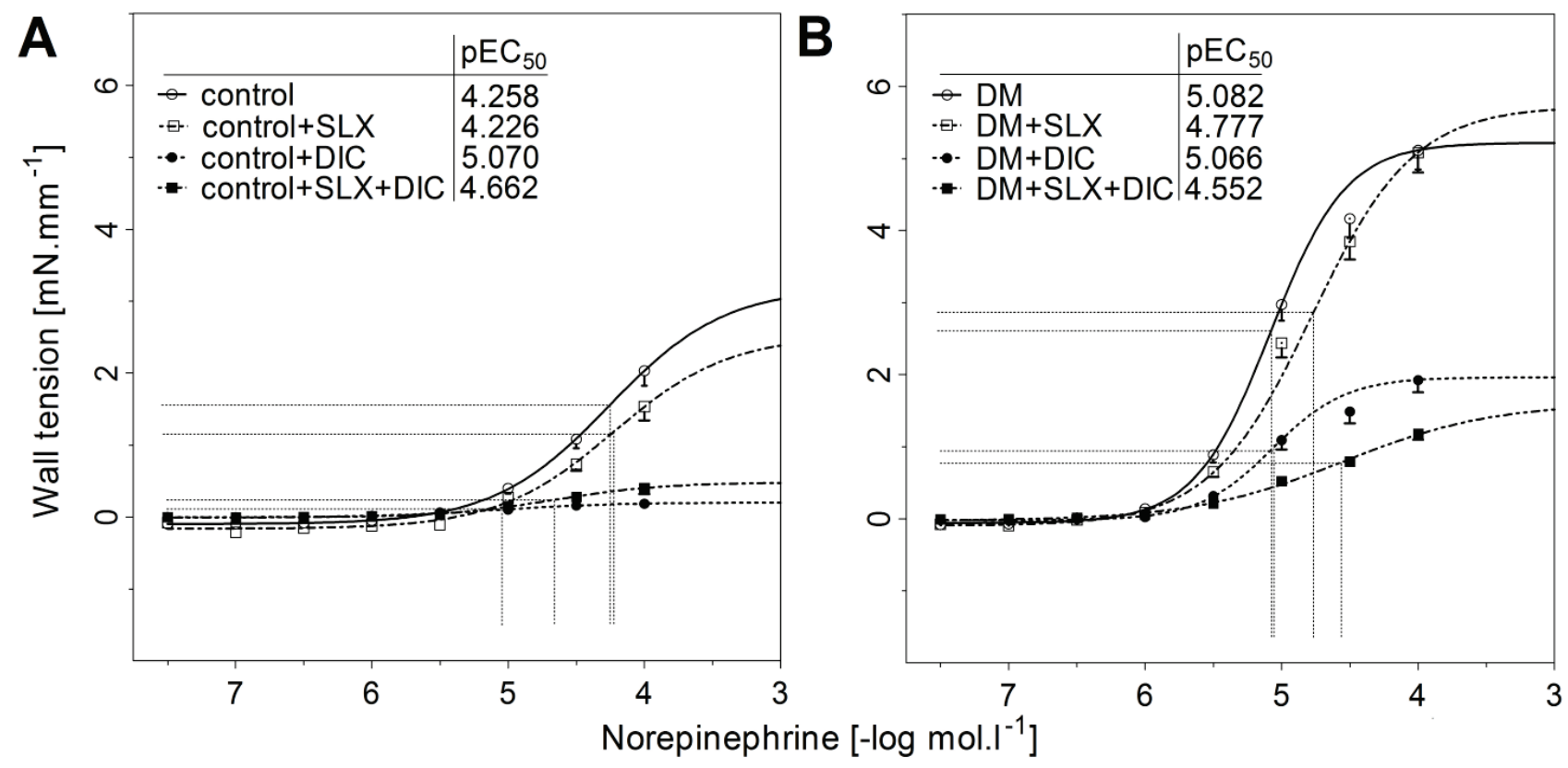

Fig. 1. Norepinephrine concentration-response curves of femoral arteries of healthy rats (A) and diabetic rats (B) recorded under normal condition and after blockade of cyclooxygenase by diclofenac (DIC, $0.01 \mathrm{~mol}^{.-I^{-1}}$ ). The thin dotted lines represent $\mathrm{pEC} \mathrm{C}_{50}$, data are expressed as arithmetic mean \pm SEM from 9-13 rings isolated as described in Methods. Curves were adjusted with non-linear regression function. 

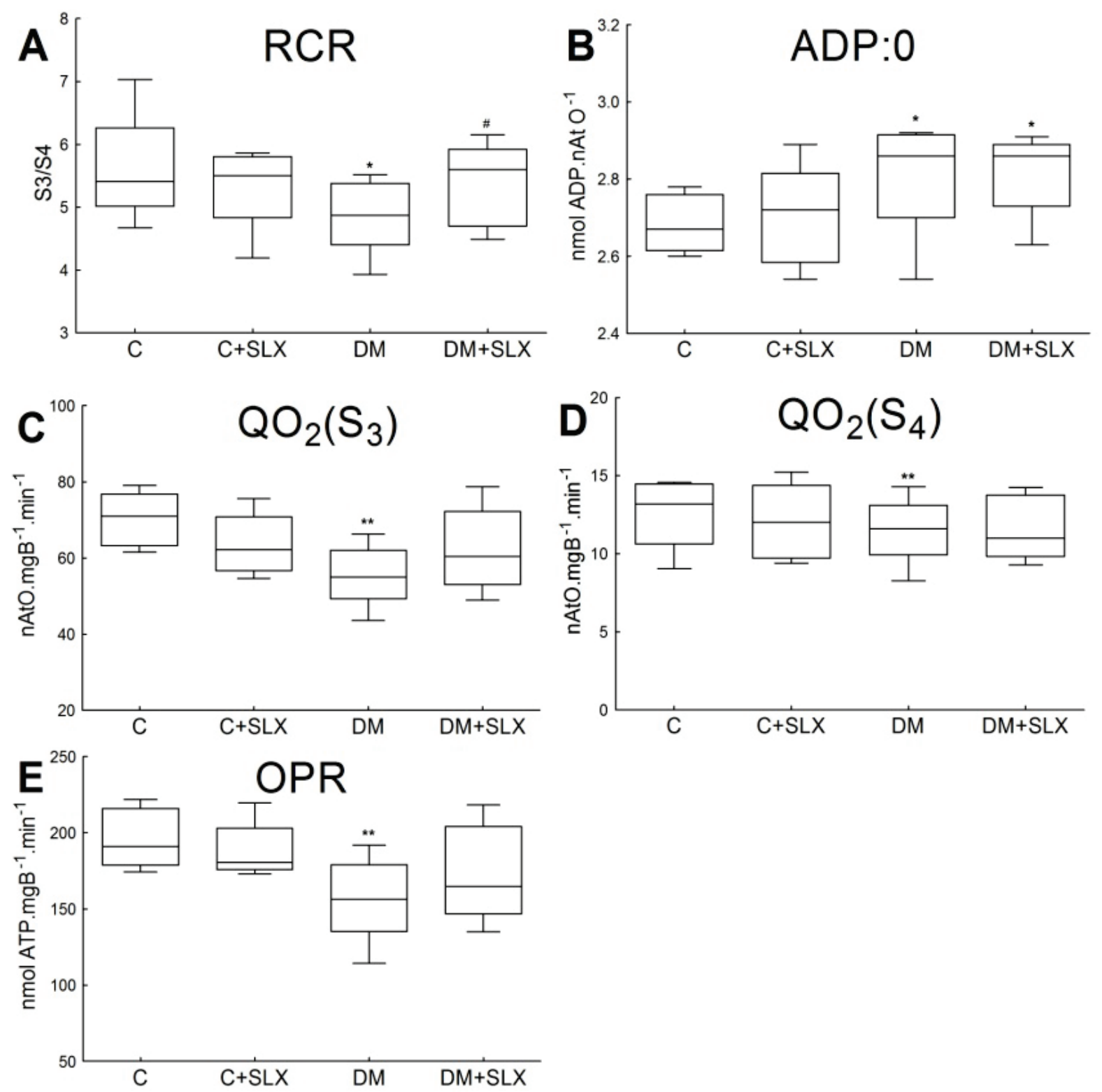

Fig. 2. Parameters of mitochondrial function following $S L X$ treatment. $R C R$ - respiratory control ratio (A), ADP:0 - coefficient of oxidative phosphorylation $(\mathbf{B}), \mathrm{QO}_{2}\left(\mathrm{~S}_{3}\right)$ - $\mathrm{ADP}$ stimulated respiration rate $(\mathbf{C}), \mathrm{QO}_{2}\left(\mathrm{~S}_{4}\right)$ - basal respiration rate $(\mathbf{D})$, OPR - oxygen phosphorylation rate (E). C - control group, C+SLX - control group administered with sulodexide, DM - diabetic group, DM+SLX diabetic group administered with sulodexide. Data are expressed as median (horizontal line), lower and upper quartile (open boxes) and minimal and maximal values (whiskers). The statistical significance was tested using the Student's t-test. Statistical significance: $* \mathrm{P}<0.05$ vs. $\mathrm{C} ; * * \mathrm{P}<0.01$ vs. $\mathrm{C} ; \# \mathrm{P}<0.05$ vs. DM.

Acetylcholine $\left(3.10^{-5}\right.$ mol..$\left.^{-1}\right)$ decreased the maximal amplitude of contraction of femoral arteries induced by highest concentration of NE $\left(10^{-4} \mathrm{~mol}^{-1} \mathrm{l}^{-1}\right)$ by $80 \%$ in control group and by $87 \%$ in SLX-treated group, respectively. In diabetic groups, acetylcholine decreased the maximal amplitude of contraction of femoral arteries by $63 \%$ in untreated and by $64 \%$ in treated group, respectively. The statistical difference between treated and untreated groups was not significant $(\mathrm{P}>0.05$; Table 1).

\section{Assessment of mitochondrial function}

All evaluated parameters of oxidative phosphorylation in the liver mitochondria of diabetic rats were significantly decreased in comparison to control values (RCR: $\mathrm{P}<0.05, \mathrm{QO}_{2}\left(\mathrm{~S}_{3}\right), \mathrm{QO}_{2}\left(\mathrm{~S}_{4}\right)$ and $\mathrm{OPR}$ : $\mathrm{P}<0.01$ ) except of the coefficient ADP:0, which was significantly increased compared to healthy rats $(\mathrm{P}<0.05$, Fig. 2). The measured parameters of liver mitochondria of control rats were not affected by SLX treatment. In diabetic rats, the coefficient RCR was found to be 
significantly increased in rats treated with SLX compared to untreated diabetic rats $(\mathrm{P}<0.05)$. Parameters of oxygen consumption rate in state 3 , state 4 , OPR and ADP:0 were not significantly affected by SLX treatment.

\section{Discussion}

It is well known fact, that vascular functions are altered by DM. Even short-term hyperglycemia can lead to augmented contractile responses, which has been confirmed also in our experiment. Impaired endotheliumdependent vasodilation has been demonstrated in various vascular beds of different animal models of diabetes and in humans with type 1 and type 2 diabetes. This may arise from several mechanisms: decreased production or enhanced inactivation of nitric oxide (NO), impairment of its diffusion to the underlying smooth muscle cells or enhanced production of EDCFs (endothelium-derived constricting factors) (De Vriese et al. 2000). Various drugs (Taddei et al. 2002, Grassi et al. 2005, Beckman 2004) have been demonstrated to improve or reverse endothelial dysfunction. SLX has been also found to reverse the damage of endothelium caused by DM, lower the number of circulating endothelial cells and improve endothelium-dependent relaxation of mesenteric arteries (Kristová et al. 2008). Many authors have described the favourable effects of various glycosaminoglycans on the integrity of endothelium (Broekhuizen et al. 2010, Połubińska et al. 2013, Vásquez et al. 2010). In our experiment, SLX treatment was able to significantly reduce augmented vascular responses, non-significantly restore endothelium-dependent vasodilation and decrease the sensitivity of arteries to norepinephrine. However, the mechanism how SLX might exert its vasoprotective action is not precisely known. We conclude that SLX has the potential to reverse vascular impairment resulting from DM, perhaps if administered for a longer time or together with appropriate anti-diabetic treatment.

Endothelial functions are dependent on the presence of well-preserved glycocalyx, which can be damaged by various stimuli like abnormal shear stress, ROS (reactive oxygen species) and hyperglycemia (Nieuwdorp et al. 2006). Glycocalyx alterations are involved in the pathogenesis of atherosclerosis and diabetic vascular complicatons (Masola et al. 2014) and can result in endothelial dysfunction, enhanced vascular permeability (Becker et al. 2010) and excessive activation of coagulation (Frati Munari 2013). There are evidences, that glycocalyx plays an important role in the release of NO as a response to the increased shear stress (Mochizuki et al. 2003). Morphofunctional integrity of the matrix of the connective tissue, mainly composed of glycosaminoglycans is therefore essential for the functional efficiency of endothelium. It has been previously described, that SLX treatment partially restores endothelial glycocalyx during DM (Broekhuizen et al. 2010). In vitro supplementation with glycosaminoglycans reverses hyperglycemia-induced impairment of permeability of the endothelium (Gouverneur et al. 2008). Moreover, SLX increases the expression of eNOS and decreases concentration of endothelin-1 (Tiurenkov et al. 2012). It is well known, that chronic hyperglycemia reduces NO bioavailability due to oxidizing cofactors of the nitric oxide synthase, consequently leading to the decreased NO production (Masha et al. 2011). Antioxidant activity of glycosaminoglycans has been described both in animal (Albertini et al. 2000) and human studies (Bilinska et al. 2009). Inhibition of excessive ROS production, increased expression of eNOS and protection of endothelial glycocalyx may all play an important role in reversing endothelial dysfunction under pathological conditions.

To investigate the participation of the cyclooxygenase in norepinephrine-induced contractions, we measured contractions in the presence of cyclooxygenase inhibitor diclofenac. Surprisingly, reduction of $\mathrm{E}_{\max }$ after blockade of the cyclooxygenase was significantly smaller in diabetic rats compared to healthy controls. Moreover, when comparing diabetic groups, this reduction was significantly higher in rats treated with SLX. To date, there is no satisfactory information about the influence of glycosaminoglycans on expression or activity of cyclooxygenase family enzymes. One study found that hyaluronan causes overexpression of cyclooxygenase resulting in subsequent $\mathrm{TXA}_{2}$ production (Sun et al. 2001). This mechanism, however, would not explain the difference in the vascular responses after the blockade of the cyclooxygenase in our experiment.

To the date we were unable to find any experimental work assessing the effect of SLX on mitochondrial functions or parameters of oxidative phosphorylation. Given their essential function in aerobic metabolism, mitochondria are intuitively of interest in regard to the pathophysiology of diabetes. Impaired mitochondrial functions during diabetes have been observed both in human subjects (Kelley et al. 2002) and animal models (Marciniak et al. 2014). Our results show 
that mitochondria isolated from livers of rats with induced DM exert reduced rates of oxygen consumption in both state 3 and state 4, decreased oxygen phosphorylation rate and respiratory control ratio compared to healthy rats. These results indicate decreased capacity of the respiratory chain and reduced rate of ATP synthesis in mitochondria in diabetic conditions, which is consistent with findings of diabetic models (Cheshchevik et al. 2011) and human DM studies (Koliaki and Roden 2013). Liver mitochondria isolated from diabetic rats treated with SLX showed increased RCR, the marker of integrity of mitochondria. Values of $\mathrm{QO}_{2}\left(\mathrm{~S}_{3}\right)$ and OPR were not statistically different in treated diabetic rats compared to untreated rats, although we observed a clear trend of improvement of these parameters. We consider this result as important because it indicates that long-term administration of SLX might inhibit the impairment of respiration chain function and mitochondria energy caused by diabetes.

In conclusion, we found augmented contractile responses and decreased endothelium-dependent relaxation responses in diabetic rats. SLX treatment significantly diminished the sensitivity of arteries to norepinephrine, non-significantly enhanced impaired endothelium-mediated relaxation responses and partially reversed the impairment of the capacity of the respiratory chain and improved rate of ATP synthesis in liver mitochondria in conditions of experimental diabetes.

\section{Conflict of Interest}

There is no conflict of interest.

\section{Acknowledgements}

The experimental work was supported by the research Grants UK/330/2014 and VEGA 1/0886/14.

\section{References}

ALBERTINI R, PASSI A, ABUJA PM, DE LUCA G: The effect of glycosaminoglycans and proteoglycans on lipid peroxidation. Int J Mol Med 6: 129-136, 2000.

ANGUS JA, WRIGHT CE: Techniques to study the pharmacodynamics of isolated large and small blood vessels. J Pharmacol Toxicol Methods 44: 395-407, 2000.

BECKER BF, CHAPPELL D, JACOB M: Endothelial glycocalyx and coronary vascular permeability: the fringe benefit. Basic Res Cardiol 105: 687-701, 2010.

BECKMAN JA, LIAO JK, HURLEY S, GARRETT LA, CHUI D, MITRA D, CREAGER MA: Atorvastatin restores endothelial function in normocholesterolemic smokers independent of changes in low-density lipoprotein. Circ Res 95: 217-223, 2004.

BILINSKA M, WOLSZAKIEWICZ J, DUDA M, JANAS J, BERESEWICZ A, PIOTROWICZ R: Antioxidative activity of sulodexide, a glycosaminoglycan, in patients with stable coronary artery disease: a pilot study. Med Sci Monit 15: CR618-CR623, 2009.

BROEKHUIZEN LN, LEMKES BA, MOOIJ HL, MEUWESE MC, VERBERNE H, HOLLEMAN F, SCHLINGEMANN RO, NIEUWDORP M, STROES ES, VINK H: Effect of sulodexide on endothelial glycocalyx and vascular permeability in patients with type 2 diabetes mellitus. Diabetologia 53: 2646-2655, 2010.

CHESHCHEVIK VT, DREMZA IK, LAPSHINA EA, ZABRODSKAYA SV, KUJAWA J, ZAVODNIK IB: Corrections by melatonin of liver mitochondrial disorders under diabetes and acute intoxication in rats. Cell Biochem Funct 29: 481-488, 2011.

CHUNYAN G, LI S, XUEPING CH, DANSHEN Z: Oxidative stress, mitochondrial damage and neurodegenerative diseases. Neural Regen Res 8: 2003-2014, 2013.

DE VRIESE AS, VERBEUREN TJ, VAN DE VOORDE J, LAMEIRE NH, VANHOUTTE PM: Endothelial dysfunction in diabetes. Br J Pharmacol 130: 963-974, 2000.

DÖNMEZ S, GÖKALP O, DOĞAN M, VURAL H, YIĞIT B: Effects of short-term hyperglycemia on the vasoconstriction of the aorta. Turk J Med Sci 44: 941-945, 2014.

ESTABROOK RW: Mitochondrial respiratory control and the polarographic measurement of the ADP: O ratios. In: Methods in Enzymology. Oxidation and Phosphorylation. ESTABROOK RW, PULLMAN ME (eds), Academic Press Inc., New York, 1967, pp 41-47. 
FÉLÉTOU M, HUANG Y, VANHOUTTE PM: Endothelium-mediated control of vascular tone: COX-1 and COX-2 products. Br J Pharmacol 164: 894-912, 2011.

FRATI MUNARI AC: Medical significance of endothelial glycocalyx. Part 2: Its role in vascular diseases and in diabetic complications. Arch Cardiol Mex 84: 110-116, 2014.

GOUVERNEUR M, BROEKHUIZEN L, MEUWESE M, MOOIJ H, STROES E, VINK H: Sulfated glycosaminoglycans restore glycocalyx barrier properties of cultured endothelial cells in hyperglycemia. FASEB J 22: 83, 2008.

GRASSI D, NECOZIONE S, LIPPI C, CROCE G, VALERI L, PASQUALETTI P, DESIDERI G, BLUMBERG JB, FERRI C: Cocoa reduces blood pressure and insulin resistance and improves endothelium-dependent vasodilation in hypertensives. Hypertension 46: 398-405, 2005.

HAN KA, PATEL Y, LTEIF AA, CHISHOLM R, MATHER KJ: Contributions of dysglycaemia, obesity, and insulin resistance to impaired endothelium-dependent vasodilation in humans. Diabetes Metab Res Rev 27: 354-361, 2011.

HOGEBOOM GH: Fractionation of cell components of animal tissues. In: Methods in Enzymology. COLOWICK SP, KAPLAN NO (eds), Academic Press Inc., New York, 1955, pp 17-19.

HOLLEMAN F, SCHLINGEMANN RO, NIEUWDORP M, STROES ES, VINK H: Effect of sulodexide on endothelial glycocalyx and vascular permeability in patients with type 2 diabetes mellitus. Diabetologia 53: 2646-2455, 2010.

HUANG Q, SHAO L, JIANG H, MIAO ZC, SHI QD, LIU SS: Effect of insulin on oxygen free radicals and oxidative phosphorylation in liver mitochondria of diabetic rats. Acta Pharmacol Sin 22: 455-458, 2001.

KELLEY DE, HE J, MENSHIKOVA EV, RITOV VB: Dysfunction of mitochondria in human skeletal muscle in type 2 diabetes. Diabetes 51: 2944-2950, 2002.

KOLIAKI C, RODEN M: Hepatic energy metabolism in human diabetes mellitus, obesity and non-alcoholic fatty liver disease. Mol Cell Endocrinol 379: 35-42, 2013.

KRISTOVÁ V, KRIŠKA M, BABÁL P, DJIBRIL MN, SLÁMOVÁ J, KURTANSKÝ A: Evaluation of endotheliumprotective effects of drugs in experimental models of endothelial damage. Physiol Res 49: 123-128, 2000.

KRISTOVÁ V, LISSSKOVÁ S, SOTNÍKOVÁ R, VOJTKO R, KURTANSKÝ A: Sulodexide improves endothelial dysfunction in streptozotocin-induced diabetes in rats. Physiol Res 57: 491-494, 2008.

LOWRY OH, ROSENBROUGH UJ, FARR AL, RANDALL RJ: Protein measurement with the folin phenol reagent. J Biol Chem 193: 265-275, 1951.

MANELLO F, LIGI D, RAFFETTO JD: Glycoasminoglycan sulodexide modulates inflammatory pathways in chronic venous disease. Int Angiol 33: 236-242, 2014.

MARCHI E, BARBANTI M, MILANI R, BRECCIA A, FINI A, GATTAVECCHIA E: Organ glycosaminoglycan distribution after intravenous and oral administration in rats. Semin Thromb Hemost 20: 297-300, 1994.

MARCINIAK C, MARECHAL X, MONTAIGNE D, NEVIERE R, LANCEL S: Cardiac contractile function and mitochondrial respiration in diabetes-related mouse models. Cardiovasc Diabetol 13: 118, 2014.

MASHA A, DINATALE S, ALLASIA S, MARTINA V: Role of the decreased nitric oxide bioavailability in the vascular complications of diabetes mellitus. Curr Pharm Biotechnol 12: 1354-1363, 2011.

MASOLA V, ZAZA G, ONISTO M, LUPO A, GAMBARO G: Glycoasminoglycans, proteoglycans and sulodexide and the endothelium: biological roles and pharmacological effects. Int Angio 33: 243-254, 2014.

MATHER K: The vascular endothelium in diabetes - a therapeutic target? Rev Endocr Metab Disord 14: 87-99, 2013.

MOCHIZUKI S, VINK H, HIRAMATSU O, KAJITA T, SHIGETO F, SPAAN JA, KAJIYA F: Role of hyaluronic acid glycoasminoglycans in shear-induced endothelium-derived nitric oxide release. Am J Physiol Heart Circ Physiol 285: H722-H726, 2003.

NIEUWDORP M, VAN HAEFTEN TW, GOUVERNEUR MC, MOOIJ HL, VAN LIESHOUT MH, LEVI M, MEIJERS JC, HOLLEMAN F, HOEKSTRA JB, VINK H, KASTELEIN JJ, STROES ES: Loss of endothelial glycocalyx during acute hyperglycemia coincides with endothelial dysfunction and coagulation activation in vivo. Diabetes 55: 480-486, 2006.

POŁUBIŃSKA A, STANISZEWSKI R, BAUM E, SUMIŃSKA-JASIŃSKA K, BRĘBOROWICZ A: Sulodexide modifies intravascular homeostasis what affects function of the endothelium $A d v$ Med Sci 58: 304-310, 2013. 
SAMMUT IA, THORNILEY MS, SIMPKIN S, FULLER BJ, BATES TE, GREEN CJ: Impairment of hepatic mitochondrial respiratory function following storage and orthotopic transplantation of rat livers. Cryobiology 36: 49-60, 1998.

SENA CM, PEREIRA AM, SEIÇA R: Endothelial dysfunction - a major mediator of diabetic vascular disease. Biochim Biophys Acta 1832: 2216-2231, 2013.

SUN LK, BECK-SCHIMMER B, OERTLI B, WÜTHRICH RP: Hyaluronan-induced cyclooxygenase-2 expression promotes thromboxane A2 production by renal cells. Kidney Int 59: 190-196, 2001.

TADDEI S, VIRDIS A, GIADONI L, SUDANO I, SALVETTI A: Effects of antihypertensive drugs on endothelial dysfunction: clinical implications Drugs 62: 265-284, 2002.

TIURENKOV IN, VORONKOV AV, SLIETSANS AA, SNIGUR GL: Effects of mexidol and sulodexide on the level of specific markers of endothelial dysfunction in animals with experimental diabetes mellitus. Eksp Klin Farmakol 75: 14-16, 2012.

VÁSQUEZ J, MATHISON Y, ROMERO-VECCHIONE E, SUÁREZ C: Effect of sulodexide on aortic vasodilation capacity and associated morphological changes in rats with streptozotocin-induced diabetes. Invest Clin 51: 467-477, 2010.

VERSARI D, DAGHINI E, VIRDIS A, GHIADONI L, TADDEI S: Endothelial dysfunction as a target for prevention of cardiovascular disease. Diabetes Care 32: 314-321, 2009. 